\title{
Экспертиза
}

ГАДЖИЕВ Камалудин Серажудинович - доктор исторических наук, профессор; главный научный сотрудник Национального исследовательского института мировой экономики и международных отношений РАН (117997, Россия, г. Москва, Профсоюзная ул., 23; k.zuhrabvi@gmail.com)

\section{О ФЕНОМЕНЕ АВТОПЛАГИАТА В ЗЕРКАЛЕ МЕТОДОЛОГИИ НАУЧНОГО ТВОРЧЕСТВА}

\begin{abstract}
Аннотация. Главное внимание в статье концентрируется на автоплагиате как новом явлении в российских общественных и гуманитарных науках. Подчеркнув его необходимость и в определенной степени полезность, автор вместе с тем обосновывает тезис, что технологию антиплагиата механически, без соответствующих поправок нельзя перенести на автоплагиат. Здесь дьявола, который кроется в деталях, значительно труднее определить, чем в антиплагиате. Обоснован тезис, согласно которому автоплагиат в той или иной форме и степени затрагивает некоторые важные аспекты, касающиеся самой природы, методологии, методов, средств и приемов научного творчества, которые предполагают использование материалов, разработок, идей в ранее опубликованных трудах одного и того же автора. Такая постановка вопроса объясняется тем фактом, что семена новых направлений, разработок, идей, задумок, смыслов, ракурсов зачастую в той или иной форме заложены в уже опубликованных трудах соответствующего автора.
\end{abstract}

Ключевые слова: антиплагиат, автоплагиат, наука, методология, политика, технология, общество, идея, теория, факты

$\mathrm{B}$ последние годы в среде научной общественности идут дискуссии и споры по вопросу о легитимности феномена автоплагиата, или самоплагиата, возможности/невозможности использования, пределах повторения тех или иных положений, идей, просто материалов из ранее опубликованных работ соответствующего автора. В некоторых изданиях, но большей частью на интернетсайтах, встречаются статьи, дискуссионные материалы, авторы которых придерживаются самых различных, порой прямо противоположных позиций - от полного запрета любых повторов в новых публикациях материалов из ранее опубликованных трудов самого автора до полного отказа от самого феномена автоплагиата как средства нарушения авторского права. В предлагаемой вниманию читателей статье предпринята попытка дать анализ данного феномена с точки зрения природы, предназначения, форм, методологии, методов и средств реализации научного творчества.

Автоплагиат - понятие производное от понятия антиплагиат, которое используется для определения того, в какой степени автор той или иной научной работы, прежде всего магистерских, кандидатских и докторских диссертаций, прибегает к заимствованиям из уже опубликованных трудов других авторов. Разработана и широко используется технология антиплагиата, призванная установить уровень и масштабы заимствований. Следует признать, что при всех возможных оговорках эта технология сыграла большую позитивную роль в ограничении (хотя и не окончательном искоренении) своего рода длинного парада претендентов из околонаучных и зачастую из далеких от науки кругов недобросовестных авторов, в т.ч. из среды чиновников всех уровней государственной власти, бизнесменов, представителей иных профессий, вожделеющих научных степеней и званий.

Что касается автоплагиата, то, естественно, он призван оздоровить ситуацию в научной среде в плане ограничения научных работников, злоупотребляющих повторными публикациями своих ранее уже вышедших в свет трудов без соответствующей доработки, или же с внесением в них тех или иных дополнений, 
не изменяющих основное содержание соответствующего труда с точки зрения поднятия его научно-аналитического уровня, актуальности и новизны. В этом плане необходимость противодействия автоплагиату не вызывает каких-либо серьезных сомнений. При всем том при объективном анализе роли данного феномена в научном творчестве возникает целый ряд сомнений, вопросов и оговорок, которые, как представляется, следовало бы учесть, чтобы избегать ненужных перегибов в этом весьма сложном и деликатном вопросе.

Тем не менее с сожалением приходится констатировать, что сам автоплагиат не лишен определенных недоработок, что, в свою очередь, предполагает необходимость дальнейшего совершенствования методов, принципов, инструментов или, иначе говоря, технологии использования данной программы. Суть вопроса заключается, помимо всего прочего, в том, что автоплагиат более или менее существенно затрагивает методологию, формы, методы, приемы научного исследования, которые при всей схожести существенно отличаются в естественных и точных науках, с одной стороны, и гуманитарных и общественных науках - с другой. Нельзя забывать, что не все в этой сфере может дать одноразовое решение, скажем, вроде решения теоремы Пуанкаре, и этим актом войти в историю науки в статусе великого ученого. Убежден в том, что на пути к этому научному подвигу Г.Я. Перельман сделал много открытий, которые стали для него труднопреодолимыми ступенями восхождения на научный олимп. Но в конечном счете он поставил последнюю, окончательную точку над $i$ в теме теоремы Пуанкаре, точно также как А. Эйнштейн - в формуле $E=m c^{2}$. В этом вопросе если в силу каких-либо факторов и возникает необходимость их переоценки, пересмотра и т.д., то для этого, как показывает история науки, потребуется много времени, возможно, века и даже тысячелетия.

Как представляется, нет необходимости доказывать, что совершенно иное положение в гуманитарных и общественных науках, в т.ч. в политологии, где сколько-нибудь приемлемые результаты достигаются в процессе постоянных проверок, переоценок, пересмотров, дополнений ранее сформулированных идей, концепций, теорий. Если согласиться с данным тезисом, при оценке автоплагиата, его значимости, преимуществах и недостатках, пределов применимости, адекватности результатов реальному содержанию в плане актуальности, новизны и т.д. никак нельзя игнорировать эту особенность научного творчества в сфере, о которой идет речь.

Зачастую технология выявления самоплагиата сводится к прогонке обслуживающим персоналом соответствующей редакции предложенной для публикации работы и выявлению процентного соотношения повторов из предыдущих работ данного автора. В соответствии с выявленными процентами соответствующая работа большей частью отклоняется с указанием этих процентов. Нельзя отрицать, что это напоминает чисто формальный подход, исходя из которого не всегда и не обязательно возможно объективно оценить, почему автор соответствующей работы решил вернуться к изложенной в прежних своих работах теме, идее, концепции, в чем именно состоит его замысел, какова научная и практическая значимость внесенных им коррективов, переоценок, новаций и т.д. Суть вопроса состоит в том, что технология автоплагиата, впрочем, как и антиплагиата, в общем и целом способна выявить, отражать и более или менее адекватно представлять, как говорится, на суд божий материи и феномены, видимые на поверхности, во многом, как говорится, исчислимые, поддающиеся описанию, оставляя как бы за скобками, или за кадром саму квинтэссенцию научного труда, т.е. ту новизну, которую автор внес в свои идеи с учетом тех, зачастую серьезных трансформаций, которые произошли в мире в целом 
и в сфере интересов самого автора со времени публикации прежних работ, используя при этом в той или иной форме, в том или ином объеме факты, возможно, также те или иные аргументы, получившие отражение в ранее опубликованных работах. Как показывает опыт, в принципе какие-нибудь 2-3, 5-6 или более страниц в зависимости от общего объема с более или менее существенной переоценкой под иным углом зрения основных положений, установок, выводов прежних работ данного автора могут представить прежнюю работу в совершенно ином свете с точки зрения ее актуальности, значимости и новизны.

Научное творчество - это особая сферадеятельностичеловека. Общеизвестно, что, взявшись за разработку той или иной темы, в процессе исследования ученый приходит к определенным результатам, положениям, выводам, которые в законченном виде формулируются в определенную идею, концепцию, теорию. Естественно, как бы завершив работу над данной темой, он берется за другую тему, разумеется, в пределах своих интересов, которые, как правило, охватывают определенный ограниченный по тематике так или иначе связанный между собой круг тем и проблем. Соответственно, изучение каждой из них способствует должному раскрытию других. Было бы глубочайшей ошибкой полагать, что, раз сформулировав их, ученый забывает о них и начинает работу как бы с чистого листа. Не является секретом тот факт, что в процессе работы над новыми темами у автора возникают новые вопросы к ранее сформулированным выводам, идеям, концепциям, теориям, которые должны быть подвергнуты переоценке под новым углом зрения, обогащая и дальше развивая их с учетом тех изменений, которые происходят в данной сфере. Новые идеи, подходы, семена новых направлений разработок, идей, задумок, смыслов, ракурсов в латентном состоянии коренятся в прежних работах автора. Поэтому зачастую каждая последующая работа представляет собой дальнейшее развитие одного и того же круга идей, подходов, разработок, что по определению невозможно без учета предыдущих работ автора. Это альфа и омега научного творчества.

Особо важное значение с рассматриваемой точки зрения имеет тот факт, что вышеупомянутые материи, более или менее успешно высвечиваемые технологией автоплагиата, как правило, определяются, анализируются, объясняются рациональными, сугубо научными методами, средствами, приемами. Если им принадлежит верховенство в сфере естественных наук, несколько по-иному обстоит дело в общественно-политической и духовной сферах. Что касается политики, то это, как и множество других общественно-исторических феноменов, представляет собой сферу, в которой главным субъектом деятельности выступает человек. Соответственно, это та сфера, где невозможно игнорировать человеческое измерение. Как известно, человек - существо не только экономическое, социологическое, политическое, но также социальнофилософское, морально-нравственное. Соответственно, важнейшие социальные и политические проблемы приобретают духовное, социокультурное, политико-культурное, морально-этическое измерения. Здесь речь может идти не только об объяснении причинно-следственных связей рациональными и научными методами, но также о постижении самих глубинных мотивов, стимулов, устремлений человека и человеческих сообществ, которые не всегда и не в должной мере можно постичь и отобразить сугубо рациональными сциентистскими методами, средствами, приемами. Иными словами, речь идет не только об объяснении вещей, но и об адекватном их понимании в смысле постижения. Прав был немецкий философ последней трети XIX - начала XX в. В. Дильтей, когда говорил, что исследование человеческих деяний, познание 
истины в сфере культуры требует внутреннего постижения, достигаемого с помощью иных средств, нежели наука.

В этом контексте представляется целесообразным и весьма полезным привести отношение к научному творчеству ряда выдающихся ученых прошлого с точки зрения дальнейшего развития идей, выдвинутых ими в своих прежних трудах. Как подчеркивал, например, И. Кант в своем знаменитом труде «Критика чистого разума» (1781 г.), средства науки составляют лишь один из инструментов выявления и изучения общественно-исторических реальностей. По его мнению, средства научного познания, взятые сами по себе, не в состоянии отобразить всю сложную гамму и палитру человеческих деяний, общественно-политических реалий. Особо важное значение в этом контексте имеют те сферы, которые связаны с разного рода теориями, идеями, ценностями. В политическом исследовании равновеликое значение имеют как объяснение, так и оценка. Без проникновения в сферу целей и идеалов не может быть речи и об адекватном изучении политики, ее предназначения, социально-философских и системных составляющих. Поэтому не случайно, признавая значимость науки, рационального, научного инструментария, призванных установить закономерности причинно-следственных связей, И. Кант вместе с тем рассматривал религиозные, нравственные, эстетические, этические начала, лежащие в основе свободы воли, в качестве неотъемлемых элементов человеческого сознания, где такой инструментарий имеет свои пределы или ограничения.

Рассуждая примерно в таком же духе, А. Шопенгауэр писал: «...почему, собственно, прошлое совершенно невозвратимо, а будущее неотвратимо, <... это также нельзя объяснить логически посредством [научных] понятий. Не объясняет это также причинность, так как она господствует только над событиями во времени, а не над самим временем... Это нельзя постигнуть из понятий, нельзя и уяснить посредством них: мы познаем это непосредственно и интуитивно, так же, как разницу между правым и левым» [Шопенгауэр 1993a: 23].

Можно количественно выразить и измерить результаты выборов различных уровней, определить их стоимость в рублях или долларах, проследить динамику численности сторонников тех или иных партий и т.д. Но столь важные категории, как благосостояние, свобода, равенство, справедливость, ни выразить таким образом, ни измерить невозможно. Или же вслед за известным английским историком и политиком лордом Дж. Актоном можно сказать, что «всякая власть развращает, абсолютная власть развращает абсолютно». Однако при этом очевидно, что весьма трудно, если не невозможно, достоверно и конкретно определить ту черту, за которой власть и развращенность становятся «абсолютными». Или же каким образом можно было бы рационально, сугубо сциентистскими аргументами в количественном измерении определить формулу американской писательницы, историка Г. Химмельфарб: «свобода тоже развращает, а абсолютная свобода развращает абсолютно». Причем сам этот постулат следует рассматривать не как неоспоримый факт в духе непреложного естественного закона, а как тенденцию, возможность реализации, формы и степень которой зависят от конкретных личностей, обстоятельств, условий и т.д. То же можно утверждать применительно к множеству других социальнополитических, морально-нравственных феноменов, таких как справедливость, истина, идеал, миссия, власть и т.д., имеющих ключевое значение для адекватного понимания политических реалий.

Важно учесть, что политика представляет собой сложную, открытую, нелинейную, незавершенную систему, способную к самоорганизации. Как известно, нелинейные уравнения в математике могут иметь несколько реше- 
ний. Подобным же образом нелинейность в социальном мире дает не один предопределенный путь развития, а несколько альтернативных, хотя спектр этих путей, или направлений, более или менее ограничен. Случайность, событийность, вероятность и необратимость составляют сущностные характеристики общественно-исторического процесса, в т.ч. политики. Немаловажное место в нем занимает момент спонтанной активности. В мировой истории известно немало случаев, когда роковая случайность или поворот событий на том или ином этапе прерывали неизбежный, казалось бы, ход вещей и, соответственно, по-своему корректировала саму историю. Множество раз случайное стечение обстоятельств оказывалось роковым для судеб целых стран и народов.

Динамизм и изменчивость мира исключают саму возможность предвидеть все последствия тех или иных общественно-исторических процессов. И действительно, как образно выразился польский исследователь Е. Шацкий, «грозовая туча может разрешиться мелким дождем, а из крохотных капель рождаются иногда бурные потоки» [Шацкий 1991: 26]. Исследование в такой динамической сфере, как мир политического, предполагает не только установление объективных причинно-следственных связей, но и вероятностный уровень суждений. В этом смысле можно говорить о вероятностной, стохастической сущности общественно-политических процессов. Поэтому феномены общественной жизни, человеческие деяния не всегда и не обязательно можно измерить и оценить некими объективными данными, универсальными или общечеловеческими мерками, якобы пригодными для всех времен и народов. Их нельзя втиснуть в прокрустово ложе арифметической формулы «дважды два - четыре», где нередко результатом бывает иная, нежели четыре, величина.

Этот тезис приобретает дополнительную обоснованность применительно к современным политическим реалиям, которые, в отличие от реалий исторических, еще не стали свершившимися фактами, а как бы находятся в постоянном процессе становления. Используя известное выражение Г.В.Ф. Гегеля «сова Минервы начинает свой полет с наступлением сумерек» применительно к историку, можно утверждать, что он имеет дело с уже свершившимися событиями, процессами, фактами. Они находятся в состоянии статики и лишены динамики, в силу чего историк может наблюдать, оценить и понять начало, развитие и конец изучаемого объекта как бы со стороны, абстрагируясь от возможностей его изменения под влиянием тех или иных сдвигов в окружающей действительности. Иначе говоря, для него сова Минервы уже начала свой полет. Если принять подобные доводы и аргументы, то можно со значительной долей убедительности утверждать, что хотя исторические реалии и невозможно с точностью фотографировать, но, тем не менее, в творческой деятельности историка объективному началу принадлежит верховенство над субъективными или иными предпочтениями.

Что касается политолога, то для него предметом исследования служат политические процессы, протекающие «здесь и сейчас», затрагивающие интересы большинства реально живущих и действующих людей с особыми интересами, предпочтениями, симпатиями, антипатиями и т.д. Будучи наблюдателем совершающихся на его глазах политических событий, человеком, воспитанным в определенной социокультурной и политико-культурной среде и имеющим собственные политические убеждения, он не всегда способен отвлечься от собственных политических приверженностей, представлений об изучаемых им материях, от симпатий, антипатий и т.д., которые во многом зависят от его принадлежности к определенному течению общественно-политической мысли. 
В условиях глобализации и информационно-телекоммуникационной революции началось и интенсифицировалось беспрецедентное убыстрение социального времени. В результате перемены настолько грандиозны и стремительны, что прошлое и будущее как бы растворяются в настоящем. Многие феномены, такие как модели социального и экономического развития, показатели экономического роста, состояние общественного мнения, устаревают настолько быстро, что человек просто не поспевает за ними. Время как бы теряет непрерывность, становится хаотическим чередованием как бы не связанных между собой отрезков. На смену понятиям потока и длительности приходят категории сиюминутности и точности. Возрастает роль вероятностных, событийных начал, динамизма и неустойчивости, необратимости и индетерминизма. В результате реальность становится как бы эфемерной, постоянно ускользающей, неуловимой, теряется ясность очертаний социальных и политических феноменов, их границы становятся аморфными, зыбкими. Зачастую исследователь не в состоянии поспевать за происходящими изменениями и процессами, тем более уловить в этом калейдоскопическом водовороте не то что истину, но и просто элементарные причинно-следственные связи.

В результате ситуация в данной сфере характеризуется преобладанием импровизации и фрагментарности, отсутствием сколько-нибудь цельных и последовательных теорий и идеологий. При таком положении вещей общественнополитические реалии весьма трудно, если не невозможно, втиснуть в прокрустово ложе каких бы то ни было искусственно сконструированных теорий, моделей вроде вышеприведенных математических аксиом. Обнаруживается, что стремление найти традиционными рациональными, сциентистскими средствами точные формулы, которые бы объективно отражали стремительно изменяющиеся общественно-политические реалии, оказывается весьма трудным, если не невозможным, делом.

Незавершенность социальной и политической действительности, ее многообразие и многовариантность оставляют место для различных ее интерпретаций. Этим объясняются бесконечные споры о сути и содержании таких понятий, как культура, мораль, национальное самосознание, политика, власть, государство, свобода, справедливость и т.д. Поэтому не существуют и не могут существовать политические теории, претендующие на то, чтобы скольконибудь точно, как бы фотографически отразить политические реалии.

Если верны эти рассуждения, то приходится признать, что в современном мире политика не дает себя фотографировать. Политический анализ - это не только научное исследование, но и в некотором роде искусство, предполагающее реконструкцию не только рациональных, поддающихся количественному исчислению мотивов, интересов людей, но также их иррациональных, подсознательных, неосознанных побуждений, которые не поддаются количественному анализу. Тут важны воображение, интуиция, психологическое проникновение и постижение. Поэтому изображение мира политики можно представить не как фотографирование, а как создание некоего образа исследуемой материи, в котором в органическом единстве объективный, научный анализ сочетается с субъективными ценностными, социально-философскими, идейно-политическими установками самого политолога. Это не точная фотокопия, а своего рода картина, которую он изображает в соответствии со своим видением предмета отображения.

Если абстрагироваться от этих принципов, которые составляют альфу и омегу научного творчества, Платона, Аристотеля, Августина Блаженного и других великих мыслителей - светочей мировой науки можно было бы причислить к отъявленным автоплагиаторам. Дело в том, что у каждого из них был опреде- 
ленный собственный круг проблем, разработок, методологических подходов, идей, концепций, теорий, которые развивались в течение всей их творческой жизни. Если обратиться к трудам Платона и Аристотеля, то обнаружится, что у них множество и множество раз повторяются одни и те же темы и понятия, такие как благо, власть, государство, идея, закон, справедливость и т.д., и т.П., которые они множество раз рассматривают с разных точек зрения, под разными углами зрения. Было бы просто абсурдом утверждать, что каждый раз они начинали эти темы как бы с чистого листа, как бы выводя за скобки свои уже, как говорится, заезженные идеи и разработки.

В этой сфере дьявол, как говорится, кроется в деталях. В случае с автоплагиатом необходимость его выявления приобретает особо важное значение, поскольку то, что на первый взгляд выглядит плагиатом, воровством тех или иных фрагментов текста, в т.ч. концептуальных положений, соответствующим автором у самого себя, в большинстве случаев таковым может и не быть, если, естественно, исходить из самой природы научного творчества.

Как известно, переиздание ранее опубликованных работ в таком обновленном качестве в научном мире является общепринятой практикой. Одно дело, когда научный сотрудник для расширения списка своих опубликованных работ предлагает ранее уже вышедшие в свет работы повторно в другие издания, возможно, с некоторыми чисто поверхностными правками. Совершенно по-другому можно оценивать работу, если она имеет своей целью дальнейшее развитие, переоценку, более или менее серьезную корректировку ранее обнародованных положений, идей, тезисов и т.д. Без признания этих реалий невозможно представить само научное творчество.

Здесь представляется уместным привести высказывания, касающиеся, как говорится, технологии научного творчества, как ее понимали и использовали, к примеру, И. Кант и А. Шопенгауэр. Так, объясняя необходимость публикации второго издания «Критики чистого разума» (первое издание - 1781 г.), И. Кант писал: «..., как и полагается, воспользовался случаем, чтобы по возможности устранить трудности и неясности, способные привести к различным недоразумениям, на которые натолкнулись, быть может не без моей вины, проницательные люди при оценке моей книги» [Кант 1994: 34]. По его словам, при подготовке второго издания ему «пришлось опустить или сократить многое такое, что несущественно для полноты целого, хотя и могло бы быть желательным для некоторых читателей, поскольку может пригодиться для других целей. Пришлось это сделать для того, чтобы дать место более ясному теперь, как я надеюсь, изложению, которое, что касается положений и даже доказательств их, по существу не изменилось, но по методу кое-где так отличается от прежнего, что не могло быть достигнуто одними лишь вставками» [Кант 1994: 36-37]. Можно ли представлять без этого труда другую известную работу Канта «Критика практического разума», опубликованную через 7 лет, в 1788 г. Показательно, что первая ее часть носит название «Критика чистого практического разума», и в ней в той или иной форме получают дальнейшее развитие идеи, сформулированные в первой работе под тем же названием, но применительно к практическому разуму.

Выражая радость по поводу предоставленной ему возможности подготовить переработку и дополнения к своему труду «Мир как воля и представление», А. Шопенгауэр писал: «Исходя из чисто эмпирических данных, из замечаний беспристрастных исследователей природы, следующих требованиям своих специальных наук, я достигаю непосредственно подлинного ядра моей метафизики, выявляю точки ее соприкосновения с естественными науками и даю тем самым в известной степени проверку моего основного догмата, который 
получает, таким образом, свое более конкретное и специальное обоснование и становится более отчетливым, точным и доступным для понимания». При этом Шопенгауэр подчеркивал, что «внесенные в это новое издание исправления почти полностью носят характер добавлений; из первого издания не устранено ничего достойного упоминания, но в первоначальный текст внесены многочисленные и в ряде случаев существенные добавления» [Шопенгауэр 1993б: 6]. К разделу второго тома книги «Мир как воля и представление» «О воле в природе» Шопенгауэр дает подзаголовок: «Обсуждение философии автора данными эмпирических наук, полученных со времени ее опубликования». Собственно говоря, второй том представляет собой дополнения к первому тому и всецело посвящен дальнейшему обоснованию сформулированных в нем идей, положений, тезисов.

Если согласиться с приведенными доводами и аргументами, то приходится признать, что в политической сфере любые идеи и теории, какими бы совершенными на первый взгляд они ни казались, нуждаются в постоянных уточнениях, переоценках, дополнениях и т.д. В данной связи нельзя не упомянуть также само собой разумеющуюся необходимость постоянных переработок, изменений, дополнений учебников по гуманитарным и общественным наукам.

Поэтому вызывает большие сомнения возможность определения коэффициента значимости второго издания как «Критики чистого разума», так и книги «Мир как воля и представление» с помощью процентного соотношения объемов старого текста названных трудов, с одной стороны, и внесенных их авторами переоценок, исправлений, дополнений - с другой.

Для зрелого, состоявшегося ученого нет надобности ради прибавления к списку своих работ публиковать еще одну работу, не имеющую значения с точки зрения внесения необходимого вклада в сферу своей научной деятельности. Что касается подрастающего поколения, то начинающему исследователю система автоплагиата, как представляется, может принести больше вреда, чем пользы, потому что эта технология без учета соответствующих оговорок, дополнительных аргументов может быть истолкована как предписание в каждой новой работе разработать, обосновать и предложить новую идею, не связанную с прежними его идеями, разработками, выводами.

К тому же нельзя не учитывать те, прямо скажем, мизерные тиражи ведущих по значимости научных журналов, в силу чего сколько-нибудь интересные идеи, разрабатываемые и выдвигаемые даже состоявшимися учеными, оказываются практически недоступными для широкой научной общественности. Даже такой очевидный факт ставит вопрос о допустимых процентах повторов в новых работах фрагментов опубликованных работ.

Если согласиться с изложенными доводами и аргументами, можно утверждать, что критерий оценки автоплагиата на основе процентного соотношения повторов из собственных ранее опубликованных работ соответствующего автора не всегда и не обязательно можно рассматривать как достаточное основание для определения коэффициента ее новизны и ценности. В этом вопросе ключевое значение могут иметь реальные новации, внесенные автором в теоретико-методологическую основу исследования, смена ракурса и угла зрения трактовки темы статьи, возможное расширение фактологической базы, поднятие научно-аналитического уровня исследования и т.д. Очевидно, что речь идет отнюдь не об отказе от самого института автоплагиата. Имеется в виду необходимость избегать возможностей ошибок в таком весьма сложном и деликатном деле, как объективная оценка работы ученого. Поэтому, как представляется, технологию антиплагиата нельзя механически без соответствующих оговорок и поправок перенести на автоплагиат в качестве абсолютно 
непогрешимого инструмента определения новизны, значимости и ценности той или иной работы ученого.

\title{
Список литературы
}

Кант И. 1994. Критика чистого разума. - Собрание сочинений. В 8 т. М.: Чоро. T. $3.741 \mathrm{c}$.

Шацкий Е. 1991. Утопия и утопическое мышление. М.: Прогресс. 405 с.

Шопенгауэр А. 1993а. Мир как воля и представление. М.: Наука. Т. І. 672 с.

Шопенгауэр А. 1993б. Мир как воля и представление. М.: Наука. Т. II. 672 с.

GADZHIEV Kamaludin Serazhudinovich, Dr.Sci. (Hist.), Professor, Chief Researcher of the National Research Institute of World Economy and International Relations, Russian Academy of Sciences (23 Profsoyuznaya St, Moscow, Russia, 117997; k.zuhrabvi@gmail.com)

\section{ABOUT THE PHENOMENON OF AUTO PLAGIARISM IN THE CONTEXT OF THE METHODOLOGY OF SCIENTIFIC CREATIVITY}

\begin{abstract}
The article focuses on auto plagiarism as a new phenomenon in Russian social and human sciences. Underlining its necessity and, to a certain extent, utility, at the same time the author attempts to substantiate the thesis that the technology of anti plagiarism cannot be mechanically transferred to auto plagiarism without the corresponding amendments. Here it is much more difficult than in the anti-plagiarism to define the devil, which is in the details. The author substantiates the thesis, according to which auto-plagiarism, in one form or another, touches upon some important aspects relating to the nature, methodology, methods, tools and techniques of scientific creativity, which involve the use of materials, developments, ideas in previously published works of the same author. This formulation of the question is explained by the fact that the seeds of new trends, developments, ideas, meanings, perspectives are often in one form or another incorporated in the already published works of the respective author.
\end{abstract}

Keywords: anti-plagiarism, auto plagiarism, science, methodology, politics, technology, society, idea, theory, facts 